\title{
Unveiling the Mechanisms Ruling the Efficient Hydrogen Evolution Reaction with Mitrofanovite $\mathrm{Pt}_{3} \mathrm{Te}_{4}$
}

Danil W. Boukhvalov, Jia Cheng, Gianluca D’Olimpio, François C. Bocquet, Chia-Nung Kuo, Anan Bari Sarkar, Barun Ghosh, Ivana Vobornik, Jun Fujii, Kuan Hsu, Li-Min Wang, Ori Azulay, Gopi Nath Daptary, Doron Naveh, Chin Shan Lue, Mykhailo Vorokhta, Amit Agarwal, Lixue Zhang,* and Antonio Politano*

Cite This: J. Phys. Chem. Lett. 2021, 12, 8627-8636

Read Online

ACCESS | 山ll Metrics \& More 回 Article Recommendations

Supporting Information

ABSTRACT: By means of electrocatalytic tests, surface-science techniques and density functional theory, we unveil the physicochemical mechanisms ruling the electrocatalytic activity of recently discovered mitrofanovite $\left(\mathrm{Pt}_{3} \mathrm{Te}_{4}\right)$ mineral. Mitrofanovite represents a very promising electrocatalyst candidate for energy-related applications, with a reduction of costs by $47 \%$ compared to pure $\mathrm{Pt}$ and superior robustness to $\mathrm{CO}$ poisoning. We show that $\mathrm{Pt}_{3} \mathrm{Te}_{4}$ is a weak topological metal with the $\mathbb{Z}_{2}$ invariant, exhibiting electrical conductivity $\left(\sim 4 \times 10^{6}\right.$ $\mathrm{S} / \mathrm{m}$ ) comparable with pure $\mathrm{Pt}$. In hydrogen evolution reaction (HER), the electrode based on bulk $\mathrm{Pt}_{3} \mathrm{Te}_{4}$ shows a very small overpotential of $46 \mathrm{mV}$ at $10 \mathrm{~mA} \mathrm{~cm}{ }^{-2}$ and a Tafel slope of $36-49 \mathrm{mV} \mathrm{dec}^{-1}$ associated with the Volmer-Heyrovsky mechanism. The outstanding ambient stability of $\mathrm{Pt}_{3} \mathrm{Te}_{4}$ also provides durability of the electrode and long-term

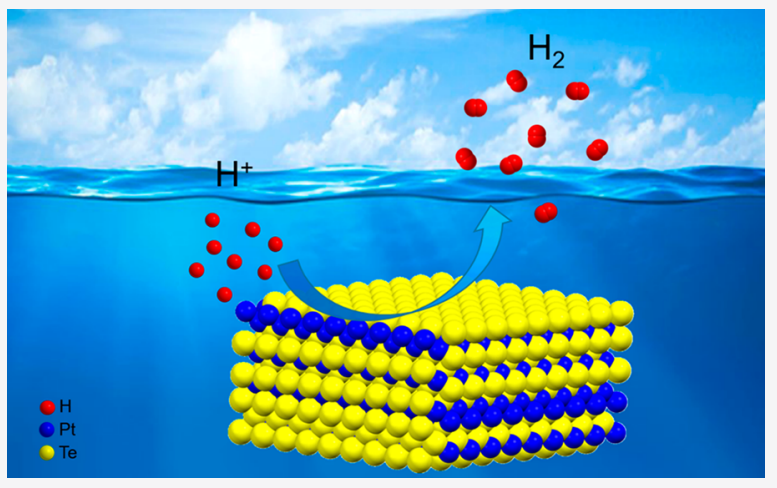
stability of its efficient catalytic performances.

I $\mathrm{n}$ the prospect of sustainable energy, molecular hydrogen represents a promising carbon-free and renewable energy carrier. In particular, HER enables achieving ultrapure hydrogen. ${ }^{1-5}$ Specifically, HER is the cathodic reaction in electrochemical water splitting $\left(2 \mathrm{H}_{2} \mathrm{O} \rightarrow 2 \mathrm{H}_{2}+\mathrm{O}_{2}\right) \cdot{ }^{1,2,5}$ Considering its crucial technological relevance, the identification of efficient electrocatalysts for HER with high activity, cheapness and long-term stability represents one of the most important open challenges in electrochemistry. ${ }^{1-5}$ To date, $\mathrm{Pt}$ is generally assumed to be the state-of-the-art HER electrocatalyst, owing to its nearly zero overpotential, relatively low Tafel slope, and good stability. ${ }^{6}$ Regrettably, the abundance of Pt on the crust of Earth is only 0.005 ppm by weight, ${ }^{7}$ and consequently, the corresponding cost is about $\$ 900 / \mathrm{oz}$, which significantly hinders its extensive technological use. Moreover, Pt electrodes are inevitably affected by $\mathrm{CO}$ poisoning, ${ }^{8}$ due to the high reactivity of $\mathrm{Pt}$ sites toward $\mathrm{CO} .{ }^{9}$ Furthermore, the typical cathode $\mathrm{Pt} / \mathrm{C}$ catalyst suffers from possible toxicity ${ }^{10}$ and dissolution during the potential cycling with reduction in its active surface area.

Subsequently, the scientific community is engaged in the quest for alternative catalysts. A possible solution relies on reducing Pt loading in Pt-based alloys, ${ }^{11,12}$ without sacrificing the catalytic activity. Among Pt alloys, Pt-based layered materials deserve particular attention ${ }^{10,13}$ for catalysis. As a matter of fact, being van der Waals materials, they can be thinned down to atomic thickness by liquid-phase exfoliation, with the possibility to achieve nanosheets with high surface area and superior catalytic activity. ${ }^{14-16}$ Especially, the transition-metal dichalcogenides (TMDs) $\mathrm{PtX}_{2}(\mathrm{X}=\mathrm{S}, \mathrm{Se}$, $\mathrm{Te})$, which crystallize in the same structure as the naturally occurring mineral "moncheite" hosts pronounced chemical/ structural flexibility. ${ }^{17,18}$

Among Pt-based layered materials, $\mathrm{PtTe}_{2}$ has been found to be the most performing electrode material for HER, with an overpotential of $0.54 \mathrm{~V}$ and a Tafel slope of $110 \mathrm{mV} \cdot \mathrm{dec}^{-1}{ }^{13}$. Notably, $\mathrm{PtTe}_{2}$ becomes successfully activated for HER upon oxidative treatment. ${ }^{19}$ Adsorption via the Volmer process is the rate-determining step for the electrochemically treated noblemetal tellurides. ${ }^{19}$ In addition, recent calculations evidence that void-containing $\mathrm{Pt}_{4} \mathrm{Te}_{7}$ could exhibit outstanding HER catalytic performance, due to the Gibbs free energy near to zero $(<0.07 \mathrm{eV}) .^{20}$ Unfortunately, all Pt-containing chalcogenides investigated to date are semimetals $\left(\mathrm{PtTe}_{2}{ }^{21}\right.$ and

Received: April 18, 2021

Accepted: July 14, 2021

Published: September 2, 2021

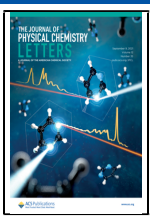



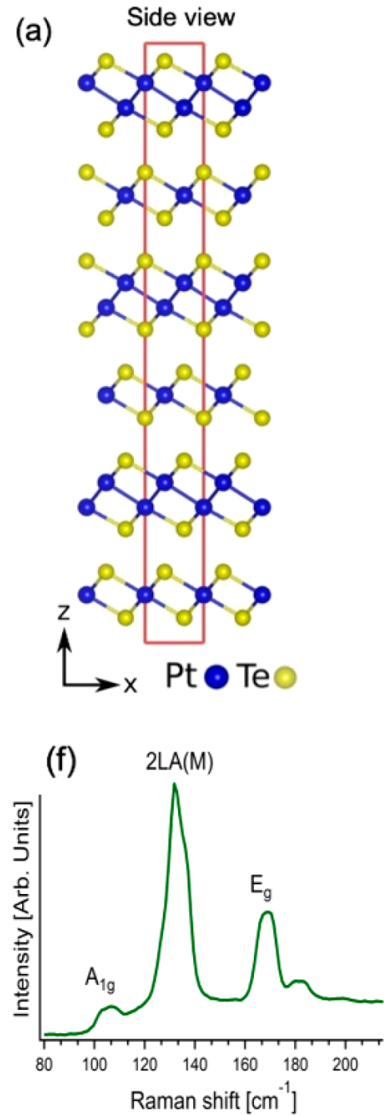

(b)

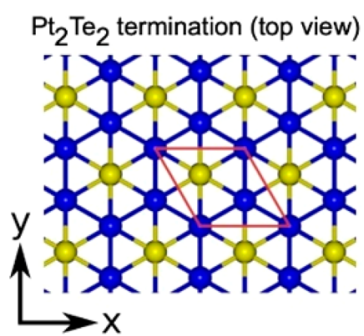

(c)

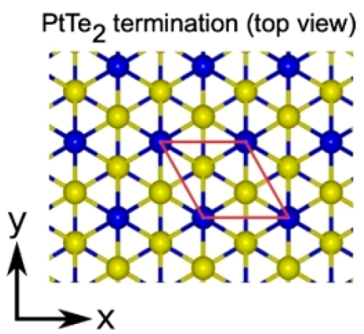

(d)

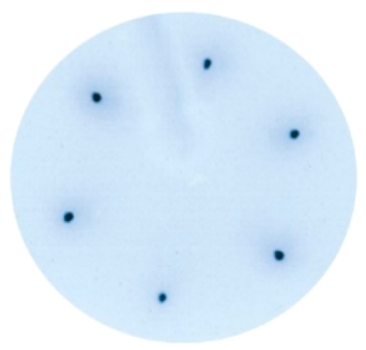

(e)

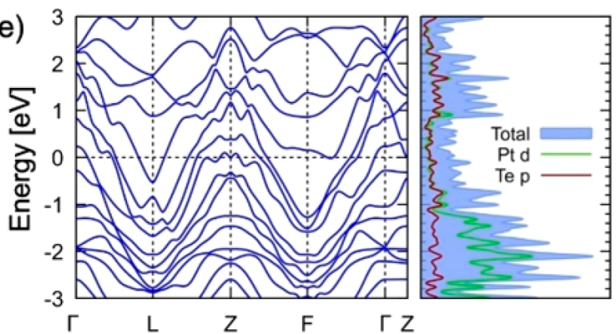

(h)
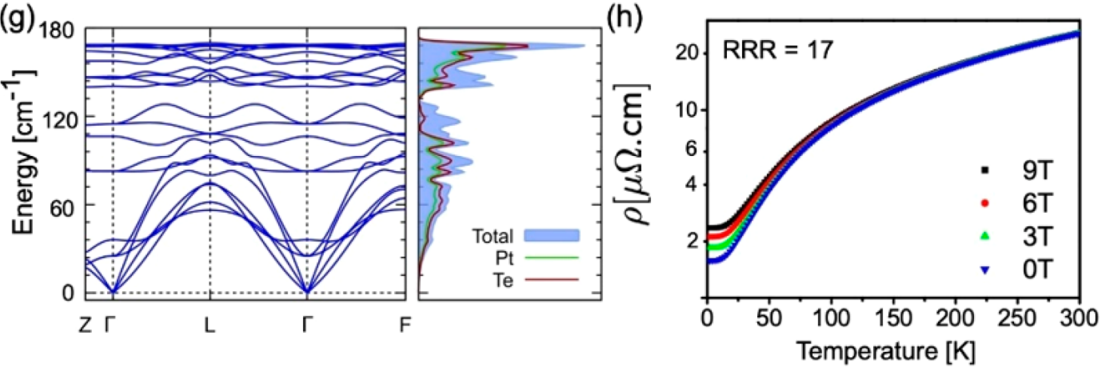

Figure 1. (a) Side view of the layered $\mathrm{Pt}_{3} \mathrm{Te}_{4}$ crystal structure, with alternate $\mathrm{PtTe}_{2}$ and $\mathrm{Pt}_{2} \mathrm{Te}_{2}$ layers stacked along the vertical direction. Panels $\mathrm{b}$ and $\mathrm{c}$ show the top view of the $\mathrm{Pt}_{3} \mathrm{Te}_{4}$ surface with (b) $\mathrm{Pt}_{2} \mathrm{Te}_{2}$ and (c) $\mathrm{PtTe}_{2}$ terminations, respectively. (d) LEED pattern obtained at an energy of $100 \mathrm{eV}$. (e) Band structure and the corresponding density of states. (f) Raman spectrum acquired using a laser with $632.8 \mathrm{~nm}$ wavelength. (g) Theoretical phonon dispersion in the primitive unit cell along with the phonon density of states. (h) Resistivity as a function of temperature, for four different values of the magnetic field, ranging from 0 to $9 \mathrm{~T}$.

$\mathrm{PtSe}_{2}^{22}$ ) or semiconductors $\left(\mathrm{PtS}_{2}^{23}\right)$. However, it is wellknown that $\mathrm{H}$ adsorption depends on the density of states (DOS) around the Fermi level, ${ }^{24-26}$, so that metallic systems would the most suitable ones for effective HER. On the other hand, surface oxidation leads to the metal-semiconductor (or insulator) transition, which usually decreases catalytic performance. Hence, the combination of features in electronic structure around Fermi level and chemical stability of metallic centers is essential for catalytic application of metallic materials.

Mitrofanovite has been recently discovered as a new natural mineral in the Kola Peninsula, Russia. ${ }^{27}$ Very recently, Bae et al. have reported the synthesis of mitrofanovite $\mathrm{Pt}_{3} \mathrm{Te}_{4}$ nanocrystals on a metallic molybdenum ditelluride $\left(\mathrm{MoTe}_{2}\right)$ template by an electrochemical method, which shows good HER performance. ${ }^{28}$ However, the relationship between the HER activity and the physicochemical properties of $\mathrm{Pt}_{3} \mathrm{Te}_{4}$ remains ambiguous, also considering the improper analysis of electronic band structure, with subsequent misleading theoretical model (see Section S16 in the Supporting Information for more details). Furthermore, such synthesis procedure is unsuitable for large-scale production and fails in reproducibility, due to its complexity. Note that the direct tellurization of $\mathrm{Pt}$ layer will produce $\mathrm{PtTe}_{2}$ instead of $\mathrm{Pt}_{3} \mathrm{Te}_{4}$ as the enthalpy of formation of $\mathrm{PtTe}_{2}$ is the lowest in the Pt-Te system. ${ }^{29,30}$
Single-crystal $\mathrm{Pt}_{3} \mathrm{Te}_{4}$ bulk samples could provide a more suitable platform to explore the catalytic activity of mitrofanovite and highlight its peculiarities. Here, we clarify the physicochemical mechanisms ruling the high efficiency in HER of mitrofanovite $\mathrm{Pt}_{3} \mathrm{Te}_{4}$ bulk crystals, which displays an overpotential as low as $46 \mathrm{mV}$ at a current density of $10 \mathrm{~mA}$ $\mathrm{cm}^{-2}$ and a Tafel slope of $36-49 \mathrm{mV} \cdot \mathrm{dec}^{-1}$ (depending on surface treatments). Moreover, we discover that $\mathrm{Pt}_{3} \mathrm{Te}_{4}$ bulk crystals exhibit high electrical conductivity $\left(3.9 \times 10^{6} \mathrm{~S} / \mathrm{m}\right)$, which contributes to its high electrocatalytic activity by decreasing the energy cost of delivery of the electrons from source to catalytic sites on the surface. Hence, mitrofanovite represents a suitable candidate as Pt-based layered electrocatalyst, with a reduced loading of $\mathrm{Pt}$, implying a decrease of costs by $47 \%$ compared to pure Pt.

Mitrofanite belongs to the trigonal space group $R \overline{3} m$ (No. 166), and it has a hexagonal structure. Bulk $\mathrm{Pt}_{3} \mathrm{Te}_{4}$ structure is formed by alternating $\mathrm{Pt}_{2} \mathrm{Te}_{2}$ and $\mathrm{PtTe}_{2}$ sublayers (constituting a septuple layer) stacked together via weak van der Waals force along the vertical direction (Figure $1 \mathrm{a}-\mathrm{c}$ ). In the $\mathrm{PtTe}_{2}$ $\left(\mathrm{Pt}_{2} \mathrm{Te}_{2}\right)$ sublayer, one (two) $\mathrm{Pt}$ atomic layers is (are) sandwiched between two Te atomic layers. The calculated value of binding energy between $\mathrm{Pt}_{3} \mathrm{Te}_{4}$ septuple layers $\left(\mathrm{Pt}_{2} \mathrm{Te}_{2}+\mathrm{PtTe}_{2}\right.$ sublayers) in the bulk is $70.39 \mathrm{~kJ}$ per formula unit, while that one between $\mathrm{Pt}_{2} \mathrm{Te}_{2}$ and $\mathrm{PtTe}_{2}$ sublayers is $78.13 \mathrm{~kJ}$ per formula unit. Calculated values are slightly higher than interlayer van der Waals bond in bulk $\mathrm{PtTe}_{2}(67.24 \mathrm{~kJ}$ per 

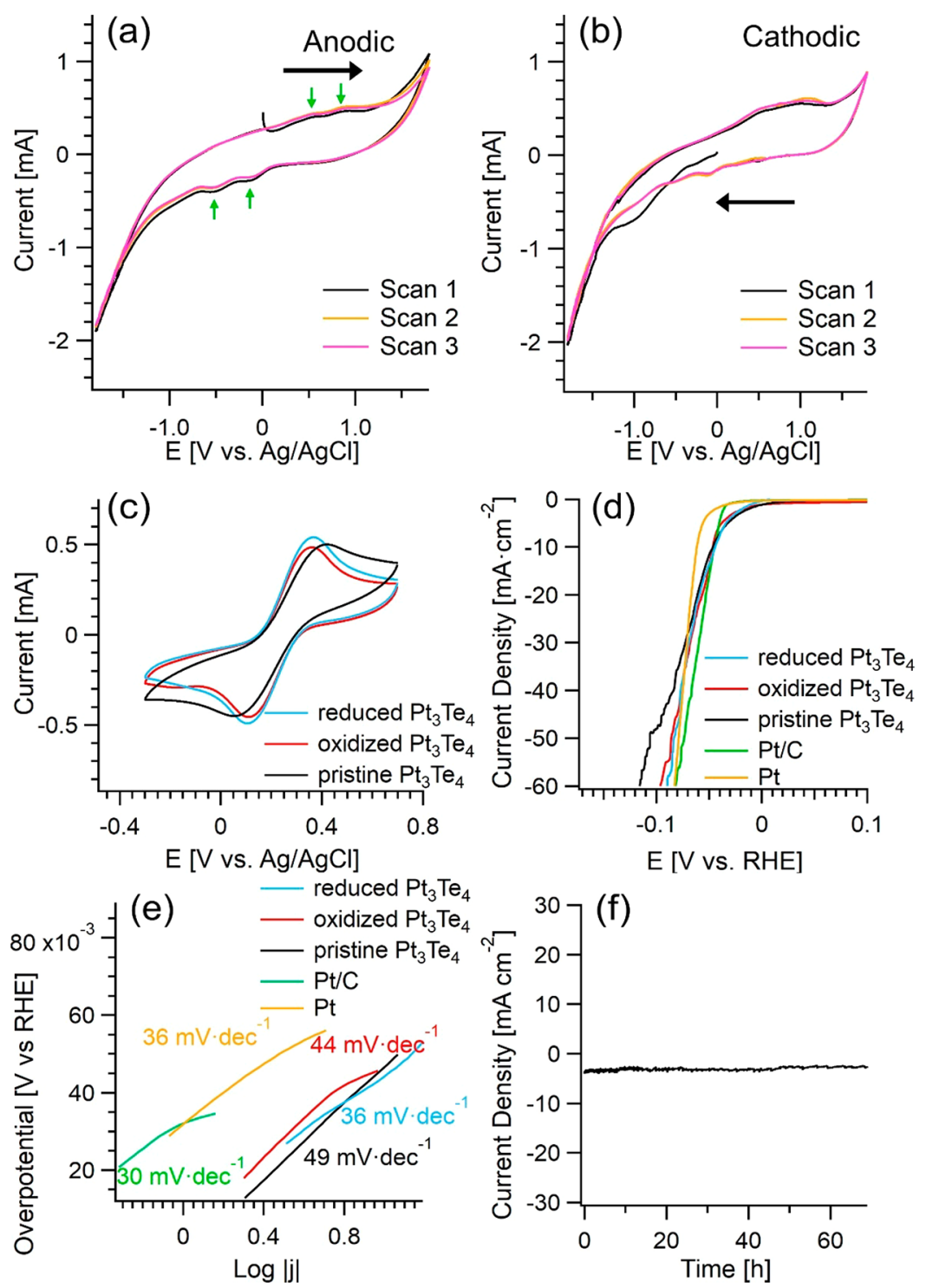

Figure 2. (a) Anodic and (b) cathodic cyclic voltammograms of $\mathrm{Pt}_{3} \mathrm{Te}_{4}$ in $0.05 \mathrm{M}$ phosphate-buffered saline electrolyte ( $\left.\mathrm{pH} 7.0\right)$ at a scan rate of $50 \mathrm{mV} \mathrm{s}^{-1}$. (c) Cyclic voltammograms of the pristine and the electrochemically treated $\mathrm{Pt}_{3} \mathrm{Te}_{4}$ in $0.1 \mathrm{M} \mathrm{KCl}$ solution containing $5 \mathrm{mM}\left[\mathrm{Fe}(\mathrm{CN})_{6}\right.$ ]$^{3-/ 4-}$ at a scan rate of $50 \mathrm{mV} \mathrm{s}^{-1}$. (d) Linear sweep voltammetry curves and (e) the corresponding Tafel plots of $\mathrm{Pt}_{3} \mathrm{Te}_{4}$ and $\mathrm{Pt}_{1} / \mathrm{C}$ catalysts in 0.5 $\mathrm{M} \mathrm{H}_{2} \mathrm{SO}_{4}$ solution at a scan rate of $2 \mathrm{mV} \mathrm{s}^{-1}$. (f) Chronopotentiometric curve without $i R$ correction for bulk $\mathrm{Pt}_{3} \mathrm{Te}_{4}$ in $0.5 \mathrm{M} \mathrm{H}_{2} \mathrm{SO}_{4}$ at a potential of $-0.053 \mathrm{~V}$ (vs RHE).

formula unit), but in both cases exfoliation in nanosheets is feasible, with the possibility to produce functional inks by liquid-phase exfoliation.

The bulk $\mathrm{Pt}_{3} \mathrm{Te}_{4}$ single crystal displays a hexagonal surface symmetry, as evinced by the analysis of the low-energy electron diffraction (LEED) pattern (Figure 1d), and three Ramanactive modes around 107, 132, and $169 \mathrm{~cm}^{-1}$ (Figure 1f). Such bands are assigned to $\mathrm{A}_{\mathrm{lg}}^{1}$, $\mathrm{E}_{\mathrm{g}}^{1}$ and $\mathrm{E}_{\mathrm{g}}^{2}$ phonons, on the basis of DFT calculations (see Section S4 of the Supporting Information for more details) of phonon dispersion (Figure $1 \mathrm{~g}$, left panel) and the corresponding density of states (DOS, Figure 1g, right panel).

Further information on structural properties is reported in the Supporting Information, with synchrotron-based X-ray diffraction (XRD) experiments (Figure S4) and highresolution transmission electron microscopy (HR-TEM) images (Figure $\mathrm{S} 6$ ). $\mathrm{Pt}_{3} \mathrm{Te}_{4}$ crystallizes in the space group $R \overline{3} m$ (166), with lattice parameters $a=3.99 \AA$ and $c=35.40 \AA$.

The electronic band-structure of $\mathrm{Pt}_{3} \mathrm{Te}_{4}$, including spinorbit coupling (SOC), is shown in Figure 1e, along with the associated DOS (see Supporting Information, Section S2, for more details on the theoretical model). The orbital-projected DOS clearly shows that the Pt-d and the Te-p orbitals contribute almost equally to the DOS near the Fermi energy, while the contribution from the Pt-d orbitals is predominant for binding energies (BEs) between 1 and $3 \mathrm{eV}$. The inspection of the band structure reveals that $\mathrm{Pt}_{3} \mathrm{Te}_{4}$ has a metallic nature, hosting several large electron pockets and a small hole pocket at the Fermi energy. Precisely, we find that $\mathrm{Pt}_{3} \mathrm{Te}_{4}$ is a weak topological metal with the $\mathbb{Z}_{2}$ invariant (see Supporting Information, Section S13). The metallic nature is experimentally confirmed by the experimental valence band (Supporting Information, Figure S2) and by transport experiments (Figure $1 \mathrm{~h})$. The $a b$-plane resistivity exhibits a clear metallic behavior 

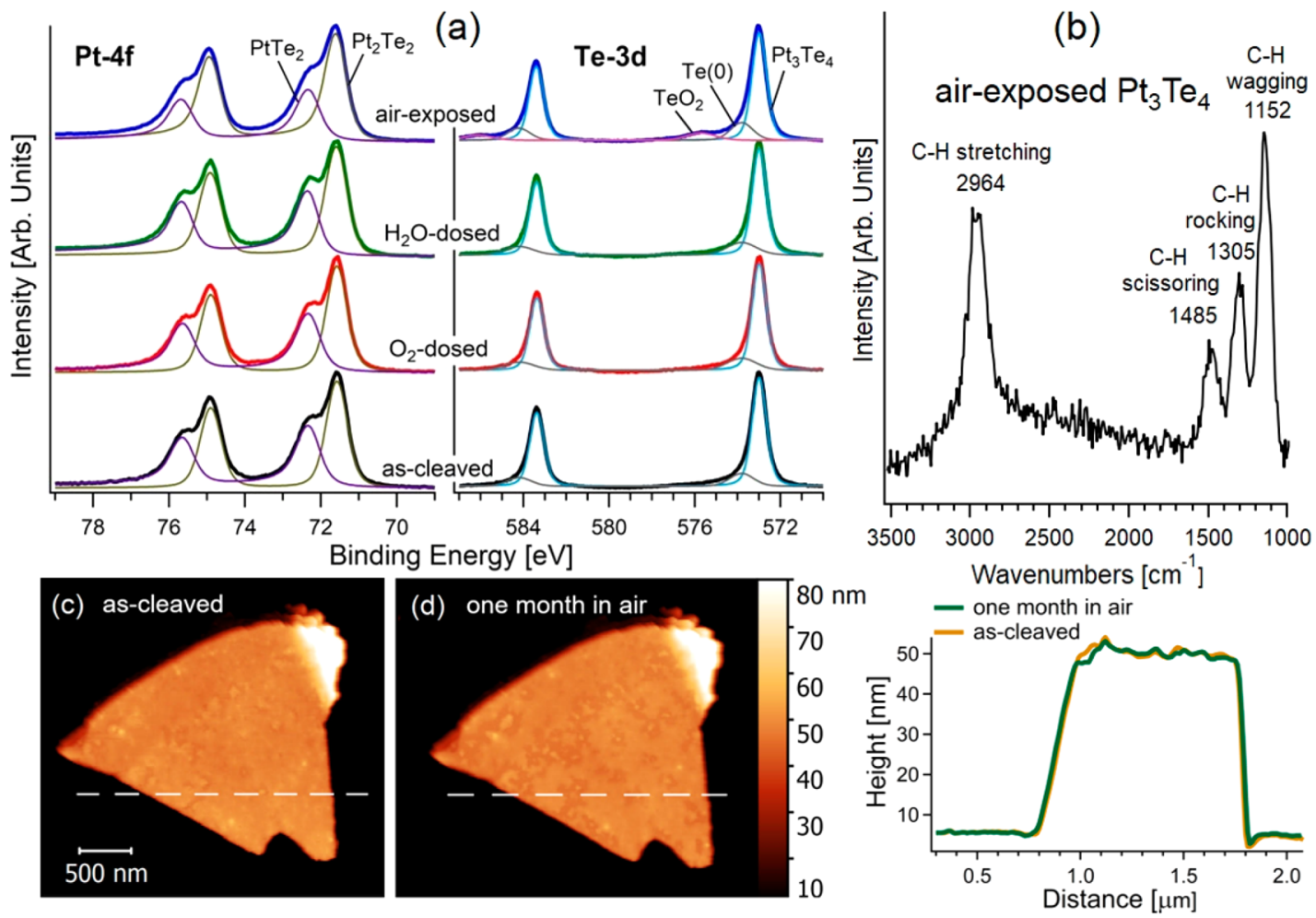

Figure 3. (a) Pt-4f and Te-3d core levels for the as-cleaved $\mathrm{Pt}_{3} \mathrm{Te}_{4}$ surface and its modifications upon exposure to $10^{10} \mathrm{~L}$ of $\mathrm{O}_{2}$ and $\mathrm{H}_{2} \mathrm{O}$ and, moreover, after storage in air. (b) Vibrational spectrum of air-exposed $\mathrm{Pt}_{3} \mathrm{Te}_{4}$, obtained by high-resolution electron energy loss spectroscopy with

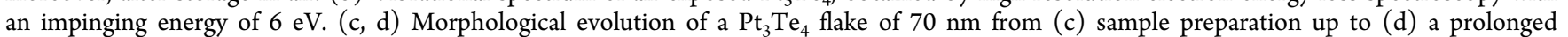
exposure to air (one month). (e) Height profile as a function of the distance along dashed white lines in panels $\mathrm{c}$ and d. Prolonged storage in air up to 1 month did not provide noticeable morphological changes.

with the residual resistivity ratio $(\mathrm{RRR}=\rho(300 \mathrm{~K}) / \rho(2 \mathrm{~K})) \sim$ 17. Resistivity at room temperature is $\sim 26 \mu \Omega \cdot \mathrm{cm}$. Correspondingly, electrical conductivity is estimated to be $\sim 4 \times 10^{6} \mathrm{~S} / \mathrm{m}$, i.e., a value comparable with that of pure $\mathrm{Pt}$ $\left(9.4 \times 10^{6} \mathrm{~S} / \mathrm{m}^{31}\right)$. This high value of the electrical conductivity arises from four pairs of bands, which lead to multiple Fermi pockets in the Brillouin zone (see Supporting Information, Figure S13 for more insights on experimental and theoretical band structure). We also evaluated the carrier concentration $n$ to be $\sim 2 \times 10^{21} \mathrm{~cm}^{-3}$ by transport experiments, with mobility of the electrons $\mu=197 \frac{\mathrm{cm}^{2}}{\mathrm{Vs}}$ (see Hall experiments in Supporting Information, Section S7).

As a recently discovered natural mineral, the electrochemistry of $\mathrm{Pt}_{3} \mathrm{Te}_{4}$ remains unknown. We directly probed its catalytic activity by testing its electrochemical behavior. Specifically, the cyclic voltammetry tests were carried out in both anodic and cathodic directions in $\mathrm{pH} 7.0$ phosphatebuffered saline electrolyte, by directly using $\mathrm{Pt}_{3} \mathrm{Te}_{4}$ bulk plate as the working electrode. In the anodic sweeps (Figure 2a), two small oxidation peaks appear around 0.49 and $0.92 \mathrm{~V}$ (vs $\mathrm{Ag} / \mathrm{AgCl}$ ) within the electrochemical stability window of the electrolyte, which should be ascribed to the oxidation of $\mathrm{Te}$ element in $\mathrm{Pt}_{3} \mathrm{Te}_{4}$, forming thermodynamically stable $\mathrm{Te}$ species with higher valence (namely, $\mathrm{TeO}_{2}$ ). As $\mathrm{Pt}_{3} \mathrm{Te}_{4}$ is composed of $\mathrm{Pt}_{2} \mathrm{Te}_{2}$ and $\mathrm{PtTe}_{2}$ sublayers (Figure 1a-c), these two oxidation peaks represent the different chemical states of the Te element in $\mathrm{Pt}_{3} \mathrm{Te}_{4}$ (see also Te-3d core levels in Figure $3 \mathrm{~b})$. Congruently, two small reduction peaks appear at around -0.11 and $-0.51 \mathrm{~V}$ (vs $\mathrm{Ag} / \mathrm{AgCl}$ ), corresponding to the reduction of Te species formed in the initial anodic sweep. The cathodic electrochemical behavior of $\mathrm{Pt}_{3} \mathrm{Te}_{4}$ (Figure 2b) is very similar to the anodic one, except that the reduction peak at around $-1.00 \mathrm{~V}$ (vs $\mathrm{Ag} / \mathrm{AgCl}$ ) in the first cathodic sweep is much more apparent, due to the electrochemical reduction of the accumulated surface oxide layer in $\mathrm{Pt}_{3} \mathrm{Te}_{4}$ in air. Compared with the electrochemistry of $\mathrm{PtTe}_{2},{ }^{13,19}$ two major differences can be distinguished between $\mathrm{Pt}_{3} \mathrm{Te}_{4}$ and $\mathrm{PtTe}_{2}$. First, there are two pairs of redox peaks for Te element in $\mathrm{Pt}_{3} \mathrm{Te}_{4}$, meanwhile there is only one pair of redox peaks for Te element in $\mathrm{PtTe}_{2}$. Second, although in neutral conditions, for values of the potential smaller than $-1.35 \mathrm{~V}$ ( $\mathrm{vs} \mathrm{Ag} / \mathrm{AgCl}$ ), the hydrogen evolution becomes prominent on $\mathrm{Pt}_{3} \mathrm{Te}_{4}$, meanwhile it is not evident on $\mathrm{PtTe}_{2}$ up to more negative values of the potential $\left(-1.8 \mathrm{~V}\right.$ vs $\left.\mathrm{Ag} / \mathrm{AgCl}^{13,19}\right)$, indicating a very promising HER catalytic activity of $\mathrm{Pt}_{3} \mathrm{Te}_{4}$. The above results illustrate the intrinsic and unique redox behaviors of $\mathrm{Pt}_{3} \mathrm{Te}_{4}$ for potentials applied in neutral conditions.

Since a fast rate of heterogeneous electron transfer is one of the prerequisites for a high-performance electrocatalyst, the heterogeneous electron transfer behavior of redox probe on $\mathrm{Pt}_{3} \mathrm{Te}_{4}$ deserves investigation. Considering the observation that $\mathrm{Pt}_{3} \mathrm{Te}_{4}$ undergoes redox behavior under different applied potentials, both the pristine $\mathrm{Pt}_{3} \mathrm{Te}_{4}$ and the same system modified by different electrochemical treatments were investigated with more details. Herein, commonly used $\left[\mathrm{Fe}(\mathrm{CN})_{6}\right]^{3-/ 4-}$ is selected as the redox probe. Definitely, both the electrochemical treatments, i.e., (i) the oxidizing treatment at a potential of $1.3 \mathrm{~V}$ (vs $\mathrm{Ag} / \mathrm{AgCl}$ ) for $5 \mathrm{~min}$ and (ii) the reducing treatment at a potential of $-1.5 \mathrm{~V}$ (vs $\mathrm{Ag} /$ $\mathrm{AgCl}$ ) for $5 \mathrm{~min}$, have a positive influence (Figure 2c). The cyclic voltammogram curves of $\left[\mathrm{Fe}(\mathrm{CN})_{6}\right]^{3-/ 4-}$ on the pristine, 
oxidized and reduced $\mathrm{Pt}_{3} \mathrm{Te}_{4}$ are similar. Interestingly, the peak-to-peak separations become even smaller after electrochemical treatments, meaning that the electrochemical redox behavior of $\left[\mathrm{Fe}(\mathrm{CN})_{6}\right]^{3-/ 4-}$ on the oxidized and reduced $\mathrm{Pt}_{3} \mathrm{Te}_{4}$ are even more reversible.

In addition, the Nyquist plots of the pristine and the electrochemically treated $\mathrm{Pt}_{3} \mathrm{Te}_{4}$ were tested in $0.1 \mathrm{M} \mathrm{KCl}$ solution containing $5 \mathrm{mM}\left[\mathrm{Fe}(\mathrm{CN})_{6}\right]^{3-} /{ }^{4-}$ (Supporting Information, Figure S17). Fitting procedure reveals the charge transfer resistance $\left(R_{\mathrm{ct}}\right)$ of the pristine, oxidized and reduced $\mathrm{Pt}_{3} \mathrm{Te}_{4}$ samples to be $102.9,84.2$, and $76.5 \Omega$, respectively. This result indicates the slightly faster charge transfer kinetics in oxidized and reduced $\mathrm{Pt}_{3} \mathrm{Te}_{4}$ than in pristine $\mathrm{Pt}_{3} \mathrm{Te}_{4}$, consistently with the cyclic voltammetry test.

To correlate the observed modifications in HER activity upon electrocatalytic treatment with changes in physicochemical and electronic properties, mitrofanovite modified by electrochemical treatments was characterized by means of XPS investigations (Supporting Information, Figure S11). Specifically, the oxidation treatment implies the emergence of $\mathrm{Te}(0)\left(\mathrm{Te}-3 \mathrm{~d}_{5 / 2}\right.$ peak at $\left.573.3 \mathrm{eV}\right)$ and $\mathrm{TeO}_{2}$ components ( $38 \%$ of the total spectral area with Te-3 $\mathrm{d}_{5 / 2}$ peak at $575.5 \mathrm{eV}$ ). Upon reduction treatment, the $\mathrm{TeO}_{2}$ component is reduced by $70 \%$. The analysis of $\mathrm{Pt}-4 \mathrm{f}$ reveals that the oxidation treatment also introduces $\mathrm{PtO}_{2}$ species (14\% of the total spectra area, Pt$4 \mathrm{f}_{7 / 2}$, at $\left.\mathrm{BE}=74.0 \mathrm{eV}\right)$. Corresponding microscopical data are reported in the Supporting Information, Figure S12. It is important to point out that XPS data clarify that no Te dissolution is induced by electrochemical treatments, as evidenced by the quantitative analysis of the $\mathrm{Pt} / \mathrm{Te}$ ratio.

These observations indicate the unique electrochemical and structural characteristics of $\mathrm{Pt}_{3} \mathrm{Te}_{4}$, which might make it be an effective electrocatalyst under different electrochemical circumstances.

Then, the electrocatalytic performance of bulk $\mathrm{Pt}_{3} \mathrm{Te}_{4}$ toward HER was evaluated by linear sweep voltammetry (LSV) in $0.5 \mathrm{M} \mathrm{H}_{2} \mathrm{SO}_{4}$ solution. For the sake of comparison, the $\mathrm{Pt}$ foil electrode was also tested under identical conditions. As shown in Figure 2d, the polarization curve indicates that the HER performance of bulk $\mathrm{Pt}_{3} \mathrm{Te}_{4}$ is very remarkable. When the current density reaches $10 \mathrm{~mA} \mathrm{~cm}{ }^{-2}$, the HER overpotentials for $\mathrm{Pt}_{3} \mathrm{~T}_{4}$ is only $46 \mathrm{mV}$, which is very close to than that of $\mathrm{Pt}$ electrode. A similar value was also reported for $\mathrm{Pt}_{3} \mathrm{Te}_{4}$ nanocrystals, ${ }^{28}$ in spite of the reduced surface-to-volume ratio in bulk compared to nanocrystals in ref 28. Moreover, all the $\mathrm{Pt}_{3} \mathrm{~T}_{4}$ samples (both pristine one and those ones modified by electrochemical treatments) show almost identical catalytic behavior at the low overpotential region. This finding highlights the unprecedented HER catalytic activity of bulk $\mathrm{Pt}_{3} \mathrm{Te}_{4}$, which is comparable to $\mathrm{Pt}$ foil and greatly surpasses all the reported group 10 transition-metal chalcogenides, such as $\mathrm{PtTe}_{2}, \mathrm{PdTe}_{2}, \mathrm{PtSe}_{2}$, and $\mathrm{PtS}_{2}$. It is well-known that the Tafel curve can reflect the reaction kinetics on the catalyst. Correspondingly, the Tafel slope can be used to analyze the reaction mechanism. Figure 2e depicts the Tafel slopes for all the $\mathrm{Pt}_{3} \mathrm{Te}_{4}$ samples and for the $\mathrm{Pt}$ foil electrode. For Pt, the Tafel slope in the low overpotential region is estimated to be $36 \mathrm{mV} \mathrm{dec}^{-1}$, indicating that the Tafel step of HER is the ratedetermining step on $\mathrm{Pt}$. For $\mathrm{Pt}_{3} \mathrm{Te}_{4}$, the calculated Tafel slopes

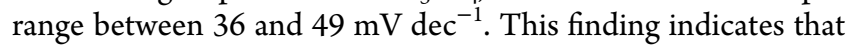
HER kinetics on $\mathrm{Pt}_{3} \mathrm{Te}_{4}$ is very fast, and it follows a VolmerHeyrovsky mechanism, in which the Heyrovsky step is the rate-determining step. All the $\mathrm{Pt}_{3} \mathrm{Te}_{4}$-based samples (pristine, oxidized, and reduced) show the similar LSV curves. Remarkably, the Tafel slopes of the oxidized and reduced $\mathrm{Pt}_{3} \mathrm{Te}_{4}$ are even smaller than that of the pristine $\mathrm{Pt}_{3} \mathrm{Te}_{4}$. Accordingly, it is evident that the electrochemical treatments can further improve the HER catalytic activity of $\mathrm{Pt}_{3} \mathrm{Te}_{4}$, which may be related to the enhanced heterogeneous electron transfer capability of $\mathrm{Pt}_{3} \mathrm{Te}_{4}$ by electrochemical treatments.

The superior catalytic activity of $\mathrm{Pt}_{3} \mathrm{Te}_{4}$ could be correlated to its morphology revealed by HR-TEM (Supporting Information, Figure S6). Explictly, the occurrence of different orientation of crystallographic axis in grains implies the formation of multiple grain boundaries with atomic structure closer to defects in $\mathrm{Pt}_{3} \mathrm{Te}_{4}$ surfaces. Such grain boundaries represent additional active sites (beyond Te vacancies), which are expected to provide a noticeable enhancement of catalytic performance.

The electrochemical stability is one of the crucial aspects in assessing the electrocatalytic performance of electrocatalysts. Specifically, the chronopotentiometric curve of $\mathrm{Pt}_{3} \mathrm{Te}_{4}$ at a potential of $-0.053 \mathrm{~V}$ (vs $\mathrm{RHE}$ ) in $\mathrm{H}_{2} \mathrm{SO}_{4}$ shows negligible attenuation in a time scale extended up to $69 \mathrm{~h}$ (Figure 2f), validating the outstanding chemical and electrocatalytic stability of $\mathrm{Pt}_{3} \mathrm{Te}_{4}$. Conversely, it has been reported that $\mathrm{PtTe}_{2}$ suffers from very low HER kinetics and, moreover, its catalytic performance changes by the electrochemical treatments. $^{13,19}$

To get more detailed information on the stability of $\mathrm{Pt}_{3} \mathrm{Te}_{4}$, we carried out a surface-science investigation regarding its chemical reactivity in oxidative and humid environments, including ambient atmosphere. The as-cleaved surface shows a splitting of the Pt-4f core level with two different doublets with $J=7 / 2$ components at BEs of 71.5 and $72.3 \mathrm{eV}$, respectively. On the other hand, Te-3d has two doublets with the $J=5 / 2$ component at 573.0 and $573.8 \mathrm{eV}$. To understand the splitting of both Pt-4f and Te-3d core levels, one should consider that the $\mathrm{Pt}_{2} \mathrm{Te}_{2}$ subunit has two different chemical environments for $\mathrm{Pt}$ atoms corresponding to $\mathrm{Pt}-\mathrm{Pt}$ and $\mathrm{Pt}-\mathrm{Te}$ bonds. Similarly, Te atoms also have two environments, corresponding to $\mathrm{Pt}-$ $\mathrm{Te}$ and $\mathrm{Te}-\mathrm{Te}$ bonds. To assign the two spectral components, we computed core-level shifts based on charge distribution in the $\mathrm{Pt}_{2} \mathrm{Te}_{2}$ subunit, finding that the charge on $\mathrm{Pt}$ sites in $\mathrm{Pt}-\mathrm{Te}$ bonds is reduced by 0.363 electrons compared to $\mathrm{Pt}-\mathrm{Pt}$ bonds, corresponding to a core-level shift by $0.8 \mathrm{eV}$.

No change in Pt-4f and Te-3d are observed after dosing $10^{10}$ $\mathrm{L}$ of $\mathrm{O}_{2}$ and $\mathrm{H}_{2} \mathrm{O}$ on as-cleaved $\mathrm{Pt}_{3} \mathrm{Te}_{4}$ (with $1 \mathrm{~L}=10^{-6}$ Torr. s). The exposure to air only affects the Te-3d core level, with the emergence of new features with $J=5 /{ }_{2}$ component at $\mathrm{BE}$ of 575.7 and $573.8 \mathrm{eV}$, corresponding to $\mathrm{TeO}_{2}$ and $\mathrm{Te}(0)$, respectively. Therefore, the outermost Te surface layer evolves into a $\mathrm{TeO}_{2}$ skin, whose thickness was estimated to be $(0.7 \pm$ $0.2) \mathrm{nm}$, according to quantitative XPS estimations ${ }^{32-34}$ (see Supporting Information, Section S11 for details). The inspection of survey XPS spectra (Supporting Information, Figure S1) also indicates the presence of carbonaceous species on the air-exposed surface. To get more insights on the nature of these $\mathrm{C}$-containing adsorbates, we carried out a vibrational investigation on the air-exposed surface, which revealed the presence of $\mathrm{CH} x$ species. As a matter of fact, the vibrational spectrum exhibited the various infrared-active modes of $\mathrm{CH} x$ species ${ }^{35-37}$ from airborne contamination: ${ }^{38}$ (i) wagging at $1152 \mathrm{~cm}^{-1}$; (ii) rocking at $1305 \mathrm{~cm}^{-1}$; (iii) scissoring at 1485 $\mathrm{cm}^{-1}$; (iv) stretching at $2964 \mathrm{~cm}^{-1}$, respectively. 
The ambient stability was also assessed by a morphological investigation by atomic force microscopy (AFM) in a time scale extended up to one month. The AFM experiments demonstrate that exposure to air did not modify the morphology of the $\mathrm{Pt}_{3} \mathrm{Te}_{4}$ surface (Figure 3, parts $\mathrm{c}$ and $\mathrm{d}$ ), as established by the minimal changes in the height profile along a specific direction (Figure 3e). Similar conclusions can be inferred from the SEM analyses of the post-mortem $\mathrm{Pt}_{3} \mathrm{Te}_{4^{-}}$ based electrode, reported in Figure S8 of the Supporting Information, which does not show any noticeable change in the morphology compared to the as-prepared electrode (Supporting Information, Figure S7).

For the sake of completeness, in Section S4 of the Supporting Information, we also report a post-mortem XPS analysis on the $\mathrm{Pt}_{3} \mathrm{Te}_{4}$ electrode (Supporting Information, Figure S3), which further supports the long-term stability of the electrode in the adopted solvents even after HER tests. Explicitly, the post-mortem XPS analysis only revealed residuals traces of $\mathrm{Fe}(\mathrm{CN})_{6}$ and $\mathrm{H}_{2} \mathrm{SO}_{4}$ solvents.

Experimental results were validated by density functional theory (DFT). First, we checked the formation energies of Te vacancies on the two different terminations of $\mathrm{Pt}_{3} \mathrm{Te}_{4}$. For the modeling of the vacancies, we removed one Te atom from the center of top layer of $3 \times 3$ supercell. We found values as high as 1.55 and $2.35 \mathrm{eV}$ for the $\mathrm{PtTe}_{2}$-terminated and $\mathrm{Pt}_{2} \mathrm{Te}_{2}$ terminated $\mathrm{Pt}_{3} \mathrm{Te}_{4}$ surfaces (Figure $4 \mathrm{a}$ ). The value of the

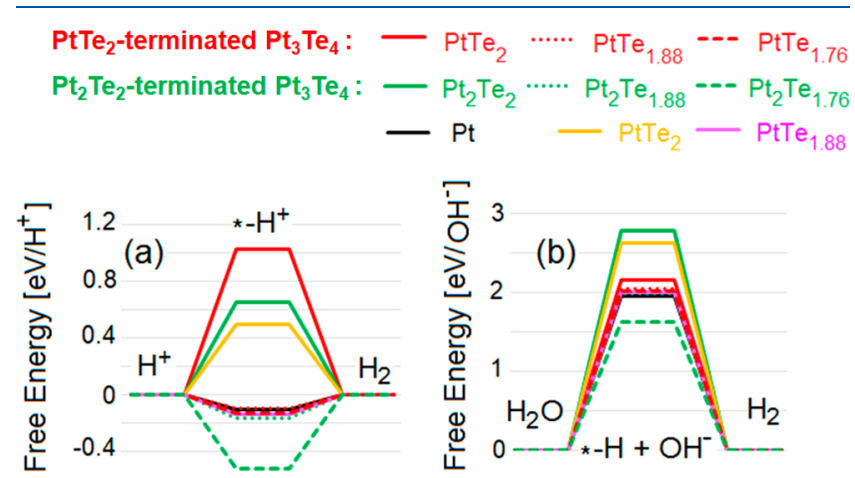

Figure 4. Free energy diagrams for HER in (a) acidic and (b) alkali media on various surfaces of $\mathrm{Pt}_{3} \mathrm{Te}_{4}$. Red lines denote results for the $\mathrm{PtTe}_{2}$-terminated $\mathrm{Pt}_{3} \mathrm{Te}_{4}$ surface, while green lines are related to the $\mathrm{Pt}_{2} \mathrm{Te}_{2}$ surface termination of $\mathrm{Pt}_{3} \mathrm{Te}_{4}$. Results for both defect-free and defective surfaces are shown. For the sake of comparison, also values for bulk $\mathrm{Pt}, \mathrm{PtTe}_{2}$, and $\mathrm{PtTe}_{1.88}$ are reported. The symbol "*” corresponds to the substrate.

formation energy for $\mathrm{PtTe}_{2}$-terminated surface is almost the same as for bulk $\mathrm{PtTe}_{2}(1.68 \mathrm{eV})$. Therefore, the probability of formation of the Te vacancies is moderate.

Successively, we assessed the chemical stability of both surface terminations. Calculations reported in Table 1. I demonstrate that, in the case of $\mathrm{CO}$, only metastable adsorption on defect-free $\mathrm{Pt}_{2} \mathrm{Te}_{2}$ surface is energetically feasible $\left(\Delta G_{\mathrm{ads}}=-1.72 \mathrm{~kJ} / \mathrm{mol}\right)$. This makes $\mathrm{Pt}_{3} \mathrm{Te}_{4}$ an ineffective catalyst for $\mathrm{CO}$ conversion. It is important to note that $\mathrm{Pt}_{3} \mathrm{Te}_{4}$ behaves differently compared to $\mathrm{Pt}$ and other $\mathrm{Pt}$ based alloys, which instead strongly suffer $\mathrm{CO}$ poisoning. A direct experimental validation of this theoretical prediction is represented by the comparative investigation reported in Figure S9 of the Supporting Information by means of the experimental technique with the highest sensitivity to $\mathrm{CO}$ adsorption, $^{39}$ i.e., HREELS.
Similarly, our theoretical model predicts that water physisorption is energetically unfavorable for all possible termination, based on the positive values of the differential Gibbs free energy $\Delta G_{\text {ads }}$ for both pristine and defective surfaces. On the other hand, oxygen physisorption at room temperature is energetically feasible, with further decomposition also energetically favorable. Note that the energy gain from oxygen decomposition on the $\mathrm{PtTe}_{2}$-terminated $\mathrm{Pt}_{3} \mathrm{Te}_{4}$ surface is about twice smaller than oxygen activation energy $(\sim 130 \mathrm{~kJ} / \mathrm{mol}) .^{12}$ Further oxidation of whole surfaces is energetically unfavorable for the defect-free $\mathrm{PtTe}_{2}$-terminated $\mathrm{Pt}_{3} \mathrm{Te}_{4}$ surface, while it is energetically favorable for other surface terminations.

Additionally, we estimated $\Delta G_{\text {ads }}$ for oxygen adsorption at room temperature in the single septuple layer of $\mathrm{Pt}_{3} \mathrm{Te}_{4}$, finding that it is energetically favorable on both the $\mathrm{Pt}_{2} \mathrm{Te}_{2}$ $(-42.39 \mathrm{~kJ} / \mathrm{mol})$ and $\mathrm{PtTe}_{2}(-11.99 \mathrm{~kJ} / \mathrm{mol})$ sides. The complete oxidation of the single septuple layer is energetically favorable at room temperature on both $\mathrm{Pt}_{2} \mathrm{Te}_{2}$ and $\mathrm{PtTe}_{2}$ sides $(-52.70$ and $-7.90 \mathrm{~kJ} / \mathrm{mol}$, respectively).

For the sake of completeness, $\Delta G_{\text {ads }}$ for oxygen adsorption at room temperature on the surface of bulk $\mathrm{PtTe}_{2}$ is -26.11 $\mathrm{kJ} / \mathrm{mol}$, with further complete oxidation energetically favorable $(-39.93 \mathrm{~kJ} / \mathrm{mol})$

Thus, oxidation of $\mathrm{Pt}_{x} \mathrm{Te}_{y}$ naturally occurs in oxidative environments, including air. As the magnitudes of the energies of each steps of oxidation are relatively high and all sites are available (as adsorption of water and carbon monoxide is unfavorable), the oxidation rate of $\mathrm{Pt}_{3} \mathrm{Te}_{4}$ is limited only by oxygen supply. In oxygen-rich environments, oxidation of the $\mathrm{Pt}_{3} \mathrm{Te}_{4}$ surface (for both bulk and atomically thin layers) will take just a few minutes with the formation of a $\mathrm{TeO}_{2}$ skin passivating the surface. The reduction of the amount of $\mathrm{Te}$ defects increases the robustness to oxidation. Notably, the rather low energy gain from the oxidation enables thermal reduction of the oxidized $\mathrm{Pt}_{3} \mathrm{Te}_{4}$ surface by heating at moderate temperatures $\left(100-200{ }^{\circ} \mathrm{C}\right)$.

To assess the suitability of $\mathrm{Pt}_{3} \mathrm{Te}_{4}$ for catalysis, we modeled HER over both $\mathrm{PtTe}_{2}$ - and $\mathrm{Pt}_{2} \mathrm{Te}_{2}$-terminated pristine and defective surfaces of bulk $\mathrm{Pt}_{3} \mathrm{Te}_{4}$. As intermediate step of HER in both media corresponds to hydrogen adsorption on catalytic substrate, we simulated adsorption of $\mathrm{H}$ on $\mathrm{Pt}$ sites. For the sake of comparison, we also performed similar calculations for the surface of the $\mathrm{PtTe}_{2}$ crystal. The calculated free energy of HER (Figure 4a,b) demonstrates that both defect-free surfaces of $\mathrm{Pt}_{3} \mathrm{Te}_{4}$ and $\mathrm{PtTe}_{2}$ are unsuitable for HER in both acidic and alkali media, without noticeable differences among bulk crystals and nanosheets of $\mathrm{Pt}_{3} \mathrm{Te}_{4}$.

However, the presence of Te vacancies drastically changes the picture. Actually, the free energy of the intermediate step of HER in the nearness of (i) single or double Te-vacancy sites in $\mathrm{PtTe}_{2}$-terminated surface $\left(\mathrm{PtTe}_{1.88}\right.$ and $\left.\mathrm{PtTe}_{1.76}\right)$ and (ii) single Te-vacancy in $\mathrm{Pt}_{2} \mathrm{Te}_{2}$-terminated surface $\left(\mathrm{Pt}_{2} \mathrm{Te}_{1.88}\right)$, assumes almost the same values of that corresponding to the $\mathrm{Pt}(111)$ surface, usually taken as a standard reference. Note that, in alkali conditions, the energy cost of water decomposition with hydrogen adsorption on $\mathrm{Pt}_{2} \mathrm{Te}_{1.76}$ surface is smaller than that for $\mathrm{Pt}(111)$. Thus, the presence of Te vacancies in the surface region plays a pivotal role in the outstanding catalytic performance of $\mathrm{Pt}_{3} \mathrm{Te}_{4}$. Note that the proposed theoretical model of defects-driven catalytic performance of $\mathrm{Pt}_{3} \mathrm{Te}_{4}$ is also valid to describe the contribution of defect-rich areas, such as grain boundaries imaged in HR-TEM images in Figure S6 of 
Table 1. Differential Enthalpy $\Delta H_{\text {ads }}$ and Differential Gibbs Free Energy $\Delta G_{\text {ads }}$ for Physical Adsorption and Differential Enthalpy of Decomposition $\Delta H_{\text {dec }}$ (all in $\mathrm{kJ} / \mathrm{mol}$ ) for Molecular Oxygen and Water on Defect-Free (i) $\mathrm{PtTe}_{2^{-}}$and (ii) $\mathrm{Pt}_{2} \mathrm{Te}_{2}-$ Terminated $\mathrm{Pt}_{3} \mathrm{Te}_{4}$ Surfaces and, Moreover, in the Nearness of Te Vacancies in These Surfaces (See Figure $\left.1 \mathrm{~b}, \mathrm{c}\right)^{a}$

\begin{tabular}{|c|c|c|c|c|c|}
\hline adsorbent & surface termination of $\mathrm{Pt}_{3} \mathrm{Te}_{4}$ & site & $\Delta H_{\text {ads }}[\mathrm{kJ} / \mathrm{mol}]$ & $\Delta G_{\text {ads }}[\mathrm{kJ} / \mathrm{mol}]$ & $\Delta H_{\mathrm{dec}}[\mathrm{kJ} / \mathrm{mol}]$ \\
\hline \multirow[t]{4}{*}{$\mathrm{CO}$} & \multirow[t]{2}{*}{$\mathrm{PtTe}_{2}$} & defect-free & -15.61 & +3.74 & \multirow[t]{2}{*}{-} \\
\hline & & Te vacancy & -12.72 & +6.63 & \\
\hline & \multirow{2}{*}{$\mathrm{Pt}_{2} \mathrm{Te}_{2}$} & defect-free & -21.07 & -1.72 & \multirow[t]{2}{*}{-} \\
\hline & & Te vacancy & -12.59 & +6.76 & \\
\hline \multirow[t]{4}{*}{$\mathrm{H}_{2} \mathrm{O}$} & \multirow[t]{2}{*}{$\mathrm{PtTe}_{2}$} & defect-free & -25.59 & +5.71 & +405.20 \\
\hline & & Te vacancy & -20.11 & +11.19 & +428.38 \\
\hline & \multirow[t]{2}{*}{$\mathrm{Pt}_{2} \mathrm{Te}_{2}$} & defect-free & -26.07 & +5.23 & +173.55 \\
\hline & & Te vacancy & -16.48 & +14.82 & -30.18 \\
\hline \multirow{4}{*}{$\mathrm{O}_{2}$} & \multirow[t]{2}{*}{$\mathrm{PtTe}_{2}$} & defect-free & -42.62 & -31.13 & $-51.78(+1.31)$ \\
\hline & & Te vacancy & -33.29 & -21.99 & $-69.37(-30.99)$ \\
\hline & \multirow[t]{2}{*}{$\mathrm{Pt}_{2} \mathrm{Te}_{2}$} & defect-free & -40.81 & -29.51 & $-98.08(-27.06)$ \\
\hline & & Te vacancy & -34.99 & -23.69 & $-162.98(-73.58)$ \\
\hline
\end{tabular}

${ }^{a}$ In the case of oxygen decomposition, we also report the differential enthalpy of the oxidation of whole surface (in parentheses).

the Supporting Information. To unveil the nature of the enhancement of catalytic activity around Te vacancies, we examined the changes in electronic structure of surface $\mathrm{Pt}$ atoms before and after hydrogenation. Calculations demonstrate that hydrogenation of $\mathrm{Pt}$ atoms does not provides visible changes of its electronic structure (Supporting Information, Figure S14a,b). The formation of Te-vacancy sites leads to the appearance of electronic states in the nearest $\mathrm{Pt}$ atoms around the Fermi level. The hydrogenation of such Pt centers eliminates these states with almost complete restoration of the electronic structure of the defect-free sample (Supporting Information, Figure $\mathrm{S} 14 \mathrm{c}, \mathrm{d})$. Note that for $\mathrm{Pt}_{2} \mathrm{Te}_{1.88}$ the magnitude of these near-zero states is larger than for $\mathrm{PtTe}_{1.88}$, which corresponds to higher catalytic performance of defective $\mathrm{Pt}_{2} \mathrm{Te}_{2}$ surface.

In conclusion, here we have shown that the mitrofanovite $\left(\mathrm{Pt}_{3} \mathrm{Te}_{4}\right)$ mineral represents a very promising candidate as an electrocatalyst for HER. Mitrofanovite is a weak topological metal with the $\mathbb{Z}_{2}$ invariant, with an electrical conductivity as high as $\sim 4 \times 10^{6} \mathrm{~S} / \mathrm{m}$, due to four pairs of bands leading to multiple Fermi pockets in the Brillouin zone. In HER, bulk $\mathrm{Pt}_{3} \mathrm{Te}_{4}$ displays a with a small overpotential of $46 \mathrm{mV}$ at $10 \mathrm{~mA}$ $\mathrm{cm}^{-2}$, and a Tafel slope of 36-49 $\mathrm{mV} \mathrm{dec}^{-1}$ associated with the Volmer-Heyrovsky mechanism. Contrary to $\mathrm{Pt}$, which highly suffers $\mathrm{CO}$ poisoning, $\mathrm{Pt}_{3} \mathrm{Te}_{4}$ is totally inert toward $\mathrm{CO}$ and, moreover, it is stable in both alkaline and acidic environments.

The excellent ambient stability of $\mathrm{Pt}_{3} \mathrm{Te}_{4}$ affords durability of the electrode, with subsequent long-term stability of its efficient catalytic performances.

Compared to pure $\mathrm{Pt}$, which represents the state-of-the-art electrode for HER, mitrofanovite $\mathrm{Pt}_{3} \mathrm{Te}_{4}$ bulk catalyst also provides comparable catalytic performances, with costs of raw materials reduced by $47 \%$. Moreover, the use of mitrofanovite could be extended to other catalytic and energy-related applications.

\section{METHODS}

Single-Crystal Growth. Single crystals of $\mathrm{Pt}_{3} \mathrm{Te}_{4}$ were grown from the self-flux method. Unlike the case of $\mathrm{PtTe}_{2}$, ${ }^{40}$ the growth window of $\mathrm{Pt}_{3} \mathrm{Te}_{4}$ is narrow. The mixtures of highpurity $\mathrm{Pt}$ foil and Te ingots with the molar ratio of 51:49 were inserted in an alumina crucible and sealed into an evacuated quartz ampule. The quartz ampule was heated to $1080{ }^{\circ} \mathrm{C}$ for $24 \mathrm{~h}$, then slowly cooled to $975^{\circ} \mathrm{C}$ at a rate of $1{ }^{\circ} \mathrm{C} / \mathrm{h}$. The excess flux was separated by centrifugation above $970{ }^{\circ} \mathrm{C}$ and mechanical polishing. Shiny plate-like $\mathrm{Pt}_{3} \mathrm{Te}_{4}$ single crystals were harvested with a dimension of $4 \times 3 \times 0.4 \mathrm{~mm}^{3}$. The flat surface of the crystal corresponds to the (001) plane, as identified by XRD analyses reported in Figure S4 of the Supporting Information.

Transport. The transport experiments on the $\mathrm{Pt}_{3} \mathrm{Te}_{4}$ single crystals were carried out using a four-point probe method in a quantum design physical property measurement system (PPMS-9).

Raman Spectroscopy. Micro-Raman spectra were obtained at room temperature by means of a LABRAM spectrometer in backscattering configuration, with a 1800 lines/mm diffraction grating and laser spot cross diameter of about $2 \mu \mathrm{m}$. The laser source is $\mathrm{He}-\mathrm{Ne}(\lambda=632.8 \mathrm{~nm})$. The optical microscope has a $100 \times$ MPLAN with numerical aperture of 0.9 .

AFM. AFM images were obtained using a Digital D5000, Veeco system working in Tapping-mode. The tip has a resonance frequency of $75 \mathrm{kHz}$.

Near-Ambient Pressure XPS. Both UHV and NAP-XPS measurements were performed at Surface Physics Laboratory in Prague using a custom-built (SPECS Surface Nano Analysis $\mathrm{GmbH}$ ) spectrometer equipped with a high-pressure (NAP) cell, monochromatized $\mathrm{Al} \mathrm{K} \alpha \mathrm{X}$-ray source, and hemispherical electron analyzer Phoibos 3500 (see ref 41 for a description of the NAP-XPS equipment). While doing the high-pressure XPS measurements, the as-cleaved sample was inserted into the NAP cell and docked to the analyzer. Then the cell was filled with $1 \mathrm{mbar}$ of $\mathrm{O}_{2}$ for $12 \mathrm{~h}$ and the XPS spectra were collected in the presence of $\mathrm{O}_{2}$ after 2 and $12 \mathrm{~h}$ of exposure. The same workflow was used for the $\mathrm{H}_{2} \mathrm{O}$ exposure.

Theoretical Methods. Modeling of the atomic structure and energetics of gas adsorption on $\mathrm{Pt}_{3} \mathrm{Te}_{4}$ was carried out using the QUANTUM-ESPRESSO code ${ }^{42}$ and the GGA-PBE functional with van der Waals (vdW) corrections, feasible for the studying of the adsorption of molecules on surfaces. ${ }^{43,44}$ Energy cutoffs of 25 and 400 Ry for the plane-wave expansion of the wave functions and the charge density, respectively, and the $4 \times 4 \times 3$ Monkhorst-Pack $k$-point grid for the Brillouin sampling were used. ${ }^{45}$

For the modeling of the surface, we used slab of two $\mathrm{Pt}_{3} \mathrm{Te}_{4}$ layers each of these layers contain $\mathrm{PtTe}_{2}$ and $\mathrm{Pt}_{2} \mathrm{Te}_{2}$ layers (see Figure 1). Note that in the slab of any number of $\mathrm{Pt}_{3} \mathrm{Te}_{4}$ layers on one surface will be $\mathrm{Pt}_{2} \mathrm{Te}_{2}$ layer and on opposite side $\mathrm{PtTe}_{2}$ 
layer. Moreover, we also considered the presence of the Te vacancies in top layer. To imitate contribution from rigid subsurface area of bulk crystals in the modeling of the surfaces, we performed optimization of the only atomic positions. In order to take into account the contribution from flexibility of nanosheets, we performed optimization of both atomic positions and lattice parameters.

The enthalpies of physical adsorption were calculated by the standard formula:

$$
\Delta H_{\text {phys }}=\left[E_{\text {host }+ \text { mol }}-\left(E_{\text {host }}+E_{\text {mol }}\right)\right]
$$

Here, $E_{\text {host }}$ is the total energy of the surface before adsorption, and $E_{\mathrm{mol}}$ is the energy of the single molecules of considered species in empty box. In the case of water adsorption, we only considered adsorption from the gaseous phase. Energy of chemical adsorption is defined as difference between the total energy of the system after and before decomposition of physically adsorbed molecule. For the case of physical adsorption, we also evaluated differential Gibbs free energy by the formula

$$
\Delta G=\Delta H-T \Delta S
$$

where $T$ is the temperature and $\Delta S$ is the change of entropy after formation molecule-substrate noncovalent bond, which was estimated similar to the gas $\rightarrow$ liquid transition and hence can be evaluated by the standard formula

$$
\Delta S=\Delta H_{\mathrm{vap}} / T
$$

where $\Delta H_{\text {vap }}$ is the empirical enthalpy of vaporization.

Methods to calculate phonons and band structure are reported in Section S3 of the Supporting Information.

Electrochemical Tests. Electrochemical tests were carried out on a Bio-Logic VSP-300 electrochemical workstation with a typical three-electrode system, in which a bulk $\mathrm{Pt}_{3} \mathrm{Te}_{4}$ plate, a $\mathrm{Pt}$ wire and a saturated $\mathrm{Ag} / \mathrm{AgCl}$ were used as the working electrode, the counter electrode, and the reference electrode, respectively. The $\mathrm{Pt} / \mathrm{C}$ electrode was prepared by casting $2 \mu \mathrm{L}$ of the dispersion ink of $1 \mathrm{mg} \mathrm{mL}{ }^{-1} \mathrm{Pt} / \mathrm{C}(20$ wt \% Pt, purchased from Sigma-Aldrich Chemical Reagent Co., Ltd.) onto a glassy carbon electrode, which was then left to dry in air. The inherent electrochemical behaviors of $\mathrm{Pt}_{3} \mathrm{Te}_{4}$ was in $0.05 \mathrm{M}$ phosphate buffered saline electrolyte ( $\mathrm{pH} 7.0)$ at a scan rate of $50 \mathrm{mV} \mathrm{s}^{-1}$. Electrochemical treatments of $\mathrm{Pt}_{3} \mathrm{Te}_{4}$ were realized by applying a potential of $1.3 \mathrm{~V}$ (vs $\mathrm{Ag} / \mathrm{AgCl}$ ) or -1.5 $\mathrm{V}$ (vs $\mathrm{Ag} / \mathrm{AgCl}$ ) on $\mathrm{Pt}_{3} \mathrm{Te}_{4}$ electrode for $5 \mathrm{~min}$ in $0.05 \mathrm{M}$ phosphate buffered saline electrolyte. The redox behavior of $\left[\mathrm{Fe}(\mathrm{CN})_{6}\right]^{3-/ 4-}$ on $\mathrm{Pt}_{3} \mathrm{Te}_{4}$ electrodes were measured in $0.1 \mathrm{M}$ $\mathrm{KCl}$ solution containing $5 \mathrm{mM}\left[\mathrm{Fe}(\mathrm{CN})_{6}\right]^{3-/ 4-}$ at a scan rate of $50 \mathrm{mV} \mathrm{s}^{-1}$. The Nyquist plots of the pristine and the electrochemically treated $\mathrm{Pt}_{3} \mathrm{Te}_{4}$ were tested in $0.1 \mathrm{M} \mathrm{KCl}$ solution containing $5 \mathrm{mM}\left[\mathrm{Fe}(\mathrm{CN})_{6}\right]^{3-/ 4-}$ at an open-circuit potential with an amplitude of $5 \mathrm{mV}$, and the frequency range is $10^{6}$ to $0.01 \mathrm{~Hz}$. For HER tests, the polarization curves were obtained using LSV in $0.5 \mathrm{M} \mathrm{H}_{2} \mathrm{SO}_{4}$ at a scan rate of $2 \mathrm{mV} \mathrm{s}^{-1}$. The chronopotentiometric test was performed in $0.5 \mathrm{M} \mathrm{H}_{2} \mathrm{SO}_{4}$ at a potential of $-0.053 \mathrm{~V}$ (vs RHE). The potentials in the HER part were calibrated to RHE, according to the following equation:

$$
E_{\mathrm{RHE}}=E_{\mathrm{Ag} / \mathrm{AgCl}}+0.059 \mathrm{pH}+0.197
$$

\section{ASSOCIATED CONTENT}

\section{SI Supporting Information}

The Supporting Information is available free of charge at https://pubs.acs.org/doi/10.1021/acs.jpclett.1c01261.

XPS, SEM, and TEM characterization of samples before and after electrochemical treatment, valence bands XPS spectra, technical details of DFT modeling, calculated infrared and Raman frequencies, electronic and band structures and detailed comparison with previous theoretical calculations, synchrotron X-ray powder diffractions patterns, transport measurements, TEM and SEM images, assessment of CO adsorption by the HREELS technique, determination of the thickness of oxide skin, and Nyquist plots (PDF)

\section{AUTHOR INFORMATION}

\section{Corresponding Authors}

Lixue Zhang - College of Chemistry and Chemical Engineering, Qingdao University, Qingdao 266071 Shandong, P. R. China; $\odot$ orcid.org/0000-0003-34304988; Email: antonio.politano@univaq.it

Antonio Politano - INSTM and Department of Physical and Chemical Sciences, University of L'Aquila, 67100 L'Aquila, $A Q$ Italy; CNR-IMM Istituto per la Microelettronica e Microsistemi, I-95121 Catania, Italy; 이이.org/00000002-4254-2102; Email: zhanglx@qdu.edu.cn

\section{Authors}

Danil W. Boukhvalov - College of Science, Institute of Materials Physics and Chemistry, Nanjing Forestry University, Nanjing 210037, P. R. China; Theoretical Physics and Applied Mathematics Department, Ural Federal University, 620002 Ekaterinburg, Russia; 이이.org/ 0000-0002-2286-3443

Jia Cheng - College of Chemistry and Chemical Engineering, Qingdao University, Qingdao 266071 Shandong, P. R. China

Gianluca D'Olimpio - INSTM and Department of Physical and Chemical Sciences, University of L'Aquila, 67100 L'Aquila, AQ, Italy; (1) orcid.org/0000-0002-6367-3945

François C. Bocquet - Peter Grünberg Institut (PGI-3), Forschungszentrum Jülich, 52425 Jülich, Germany; Jülich Aachen Research Alliance (JARA), Fundamentals of Future Information Technology, 52425 Jülich, Germany; (1) orcid.org/0000-0002-9471-4439

Chia-Nung Kuo - Department of Physics, National Cheng Kung University, 70101 Tainan, Taiwan

Anan Bari Sarkar - Department of Physics, Indian Institute of Technology Kanpur, Kanpur 208016, India

Barun Ghosh - Department of Physics, Indian Institute of Technology Kanpur, Kanpur 208016, India

Ivana Vobornik - CNR-IOM, TASC Laboratory, Area Science Park-Basovizza, 34139 Trieste, Italy

Jun Fujii - CNR-IOM, TASC Laboratory, Area Science ParkBasovizza, 34139 Trieste, Italy

Kuan Hsu - Department of Physics/Graduate Institute of Applied Physics, National Taiwan University, Taipei 10617, Taiwan

Li-Min Wang - Department of Physics/Graduate Institute of Applied Physics, National Taiwan University, Taipei 10617, Taiwan 
Ori Azulay - Faculty of Engineering and Institute of Nanotechnology, Bar-Ilan University, Ramat-Gan 52900, Israel

Gopi Nath Daptary - Department of Physics and Institure of Nanotechnology, Bar-Ilan University, Ramat-Gan 52900, Israel

Doron Naveh - Faculty of Engineering and Institute of Nanotechnology, Bar-Ilan University, Ramat-Gan 52900, Israel; @ orcid.org/0000-0003-1091-5661

Chin Shan Lue - Department of Physics, National Cheng Kung University, 70101 Tainan, Taiwan

Mykhailo Vorokhta - Charles University, 18000 Prague, Czechia; 이이이.org/0000-0001-8382-7027

Amit Agarwal - Department of Physics, Indian Institute of Technology Kanpur, Kanpur 208016, India

Complete contact information is available at: https://pubs.acs.org/10.1021/acs.jpclett.1c01261

\section{Author Contributions}

D.W.B. and J.C. contributed equally.

\section{Author Contributions}

The project was conceived and coordinated by A.P. Electrocatalytic tests were performed by J.C. and L.Z. Calculations were performed by D.W.B. for catalysis and B.G., A.B.S., and A.A. for band structure. F.C.B. performed LEED experiments. I.V. and J.F. performed experiments of valence-band spectra. C.-N.K., C.S.L., and A.P. grew samples. A.P. performed HREELS experiments. M.V. performed XPS spectra. G.D'O. performed AFM experiments. O.A., G.N.D. and D.N. performed transport experiments. The manuscript was written by D.W.B., L.Z., and A.P., with contribution from all authors regarding their parts.

\section{Notes}

The authors declare no competing financial interest.

\section{ACKNOWLEDGMENTS}

L.Z. acknowledges funding by the National Natural Science Foundation of China (Nos. 21775078 and 22075159) and Taishan Scholar Program (No. tsqn202103058). F.C.B. acknowledges funding by the DFG through the SFB 1083 Structure and Dynamics of Internal Interfaces (Project A 12). D.W.B. acknowledged support Ministry of Science and Higher Education of the Russian Federation (through the basic part of the government mandate, Project No. FEUZ-2020-0060) and Jiangsu Innovative and Entrepreneurial Talents Project. I.V. and J.F. thank NFFA-Trieste.

\section{REFERENCES}

(1) Ran, N.; Sun, B.; Qiu, W.; Song, E.; Chen, T.; Liu, J. Identifying Metallic Transition-Metal Dichalcogenides for Hydrogen Evolution through Multilevel High-Throughput Calculations and Machine Learning. J. Phys. Chem. Lett. 2021, 12, 2102-2111.

(2) Wang, M.; Ma, W.; Lv, Z.; Liu, D.; Jian, K.; Dang, J. Co-Doped $\mathrm{Ni}_{3} \mathrm{~N}$ Nanosheets with Electron Redistribution as Bifunctional Electrocatalysts for Efficient Water Splitting. J. Phys. Chem. Lett. 2021, 12, 1581-1587.

(3) Wu, F.; Zhan, S.; Yang, L.; Zhuo, Z.; Wang, X.; Li, X.; Luo, Y.; Jiang, J. Spatial Confinement of a Carbon Nanocone for an Efficient Oxygen Evolution Reaction. J. Phys. Chem. Lett. 2021, 12, 22522258.

(4) Yu, T.; Wang, C.; Yan, X.; Yang, G.; Schwingenschlogl, U. Anisotropic Janus $\mathrm{SiP}_{2}$ Monolayer as a Photocatalyst for Water Splitting. J. Phys. Chem. Lett. 2021, 12, 2464-2470.
(5) Zhang, H.; Zhang, M.; Jia, Y.; Geng, L.; Yin, B.; Li, S.; Luo, Z.; Pan, F. Vanadium Cluster Neutrals Reacting with Water: Superatomic Features and Hydrogen Evolution in a Fishing Mode. J. Phys. Chem. Lett. 2021, 12, 1593-1600.

(6) Cheng, N.; Stambula, S.; Wang, D.; Banis, M. N.; Liu, J.; Riese, A.; Xiao, B.; Li, R.; Sham, T.-K.; Liu, L.-M.; et al. Platinum SingleAtom and Cluster Catalysis of the Hydrogen Evolution Reaction. Nat. Commun. 2016, 7, 1-9.

(7) Haynes, W. M., Abundance of Elements in the Earth's Crust and in the Sea. In CRC handbook of chemistry and physics; Taylor \& Francis: 2014; pp 14-18.

(8) He, J.; Shen, Y.; Yang, M.; Zhang, H.; Deng, Q.; Ding, Y. The Effect of Surface Strain on the CO-Poisoned Surface of Pt Electrode for Hydrogen Adsorption. J. Catal. 2017, 350, 212-217.

(9) Chen, Q.-S.; Berna, A.; Climent, V.; Sun, S.-G.; Feliu, J. M. Specific Reactivity of Step Sites Towards CO Adsorption and Oxidation on Platinum Single Crystals Vicinal to Pt (111). Phys. Chem. Chem. Phys. 2010, 12, 11407-11416.

(10) Rosli, N. F.; Mayorga-Martinez, C. C.; Latiff, N. M.; Rohaizad, N.; Sofer, Z.; Fisher, A. C.; Pumera, M. Layered $\mathrm{PtTe}_{2}$ Matches Electrocatalytic Performance of $\mathrm{Pt} / \mathrm{C}$ for Oxygen Reduction Reaction with Significantly Lower Toxicity. ACS Sustainable Chem. Eng. 2018, 6, 7432-7441.

(11) Schwämmlein, J. N.; Stühmeier, B. M.; Wagenbauer, K.; Dietz, H.; Tileli, V.; Gasteiger, H. A.; El-Sayed, H. A. Origin of Superior Hor/Her Activity of Bimetallic Pt-Ru Catalysts in Alkaline Media Identified Via Ru@ Pt Core-Shell Nanoparticles. J. Electrochem. Soc. 2018, 165, H229.

(12) Kobayashi, D.; Kobayashi, H.; Wu, D.; Okazoe, S.; Kusada, K.; Yamamoto, T.; Toriyama, T.; Matsumura, S.; Kawaguchi, S.; Kubota, Y.; et al. Significant Enhancement of Hydrogen Evolution Reaction Activity by Negatively Charged Pt through Light Doping of W. J. Am. Chem. Soc. 2020, 142, 17250-17254.

(13) Chia, X.; Adriano, A.; Lazar, P.; Sofer, Z.; Luxa, J.; Pumera, M. Layered Platinum Dichalcogenides $\left(\mathrm{PtS}_{2}, \mathrm{PtSe}_{2}\right.$, and $\left.\mathrm{PtTe}_{2}\right)$ Electrocatalysis: Monotonic Dependence on the Chalcogen Size. Adv. Funct. Mater. 2016, 26, 4306-4318.

(14) Petroni, E.; Lago, E.; Bellani, S.; Boukhvalov, D. W.; Politano, A.; Gürbulak, B.; Duman, S.; Prato, M.; Gentiluomo, S.; OropesaNuñez, R.; Panda, J. K.; Toth, P. S.; Del Rio Castillo, A. E.; Pellegrini, V.; Bonaccorso, F. Liquid-Phase Exfoliated Indium-Selenide Flakes and Their Application in Hydrogen Evolution Reaction. Small 2018, $14,1800749$.

(15) Song, F.; Hu, X. Exfoliation of Layered Double Hydroxides for Enhanced Oxygen Evolution Catalysis. Nat. Commun. 2014, 5, 1-9.

(16) Anemone, G.; Garnica, M.; Zappia, M.; Aguilar, P. C.; Al Taleb, A.; Kuo, C. N.; Lue, C. S.; Politano, A.; Benedek, G.; de Parga, A. L. V.; Miranda, R.; Farias, D. Experimental Determination of Surface Thermal Expansion and Electron-Phonon Coupling Constant of 1t$\mathrm{PtTe}_{2}$. 2D Mater. 2020, 7, 025007.

(17) Krivovichev, V. G.; Krivovichev, S. V.; Charykova, M. V. Tellurium Minerals: Structural and Chemical Diversity and Complexity. Minerals 2020, 10, 623.

(18) Missen, O. P.; Ram, R.; Mills, S. J.; Etschmann, B.; Reith, F.; Shuster, J.; Smith, D. J.; Brugger, J. Love Is in the Earth: A Review of Tellurium (Bio)Geochemistry in Surface Environments. Earth-Sci. Rev. 2020, 204, 103150.

(19) Chia, X.; Sofer, Z.; Luxa, J.; Pumera, M. Layered Noble Metal Dichalcogenides: Tailoring Electrochemical and Catalytic Properties. ACS Appl. Mater. Interfaces 2017, 9, 25587-25599.

(20) Lei, B.; Zhang, Y.-Y.; Du, S.-X. Prediction of Structured VoidContaining 1T-PtTe2Monolayer with Potential Catalytic Activity for Hydrogen Evolution Reaction. Chin. Phys. B 2020, 29, 058104.

(21) Hu, X.; Wong, K. P.; Zeng, L.; Guo, X.; Liu, T.; Zhang, L.; Chen, Q.; Zhang, X.; Zhu, Y.; Fung, K. H.; et al. Infrared NanoImaging of Surface Plasmons in Type-II Dirac Semimetal $\mathrm{PtTe}_{2}$ Nanoribbons. ACS Nano 2020, 14, 6276-6284.

(22) Zhang, K.; Yan, M.; Zhang, H.; Huang, H.; Arita, M.; Sun, Z.; Duan, W.; Wu, Y.; Zhou, S. Experimental Evidence for Type-II Dirac 
Semimetal in $\mathrm{PtSe}_{2}$. Phys. Rev. B: Condens. Matter Mater. Phys. 2017, 96, 125102.

(23) Xu, H.; Huang, H.-P.; Fei, H.; Feng, J.; Fuh, H.-R.; Cho, J.; Choi, M.; Chen, Y.; Zhang, L.; Chen, D.; et al. Strategy for Fabricating Wafer-Scale Platinum Disulfide. ACS Appl. Mater. Interfaces 2019, 11, 8202-8209.

(24) Krukowski, S.; Kempisty, P.; Strąk, P. Fermi Level Influence on the Adsorption at Semiconductor Surfaces-Ab Initio Simulations. J. Appl. Phys. 2013, 114, 063507.

(25) Nilsson, A.; Pettersson, L. G. M.; Hammer, B.; Bligaard, T.; Christensen, C. H.; Nørskov, J. K. The Electronic Structure Effect in Heterogeneous Catalysis. Catal. Lett. 2005, 100, 111-114.

(26) Santos, E.; Schmickler, W. D-Band Catalysis in Electrochemistry. ChemPhysChem 2006, 7, 2282-2285.

(27) Subbotin, V. V.; Vymazalová, A.; Laufek, F.; Savchenko, Y. E.; Stanley, C. J.; Gabov, D. A.; Plášil, J. Mitrofanovite, $\mathrm{Pt}_{3} \mathrm{Te}_{4}$, a New Mineral from the East Chuarvy Deposit, Fedorovo-Pana Intrusion, Kola Peninsula, Russia. Mineral. Mag. 2019, 83, 523-530.

(28) Bae, D.; Park, K.; Kwon, H.; Won, D.; Ling, N.; Baik, H.; Yang, J.; Park, H. J.; Cho, J.; Yang, H.; et al. Mitrofanovite, Layered Platinum Telluride, for Active Hydrogen Evolution. ACS Appl. Mater. Interfaces 2021, 13, 2437-2446.

(29) Tong, X.-W.; Lin, Y.-N.; Huang, R.; Zhang, Z.-X.; Fu, C.; Wu, D.; Luo, L.-B.; Li, Z.-J.; Liang, F.-X.; Zhang, W. Direct Tellurization of $\mathrm{Pt}$ to Synthesize 2D $\mathrm{PtTe}_{2}$ for High-Performance Broadband Photodetectors and NIR Image Sensors. ACS Appl. Mater. Interfaces 2020, 12, 53921-53931.

(30) Guo, C.; Huang, L.; Li, C.; Shang, S.; Du, Z. Thermodynamic Modeling of the Pt-Te and Pt-Sb-Te Systems. J. Electron. Mater. 2015, 44, 2638-2650.

(31) White, G. K. Experimental Techniques in Low-Temperature Physics; 1987.

(32) Walton, J.; Alexander, M.; Fairley, N.; Roach, P.; Shard, A. Film Thickness Measurement and Contamination Layer Correction for Quantitative XPS. Surf. Interface Anal. 2016, 48, 164-172.

(33) Alexander, M. R.; Thompson, G. E.; Zhou, X.; Beamson, G.; Fairley, N. Quantification of Oxide Film Thickness at the Surface of Aluminium Using XPS. Surf. Interface Anal. 2002, 34, 485-489.

(34) Sciortino, L.; Lo Cicero, U.; Magnano, E.; Pís, I.; Barbera, M. Surface Investigation and Aluminum Oxide Estimation on Test Filters for the Athena X-Ifu and Wfi Detectors. Proc. SPIE 2016, 9905, 990566.

(35) Wiercigroch, E.; Szafraniec, E.; Czamara, K.; Pacia, M. Z.; Majzner, K.; Kochan, K.; Kaczor, A.; Baranska, M.; Malek, K. Raman and Infrared Spectroscopy of Carbohydrates: A Review. Spectrochim. Acta, Part A 2017, 185, 317-335.

(36) Steininger, H.; Ibach, H.; Lehwald, S. Surface Reactions of Ethylene and Oxygen on $\mathrm{Pt}(111)$. Surf. Sci. 1982, 117, 685-698.

(37) Nevins, N.; Allinger, N. L. Molecular Mechanics (Mm4) Vibrational Frequency Calculations for Alkenes and Conjugated Hydrocarbons. J. Comput. Chem. 1996, 17, 730-746.

(38) Li, Z.; Wang, Y.; Kozbial, A.; Shenoy, G.; Zhou, F.; McGinley, R.; Ireland, P.; Morganstein, B.; Kunkel, A.; Surwade, S. P.; Li, L.; Liu, H. Effect of Airborne Contaminants on the Wettability of Supported Graphene and Graphite. Nat. Mater. 2013, 12, 925-931.

(39) Politano, A.; Chiarello, G. Vibrational Investigation of Catalyst Surfaces: Change of the Adsorption Site of CO Molecules Upon Coadsorption. J. Phys. Chem. C 2011, 115, 13541-13553.

(40) Dey, S.; Jain, V. K. Platinum Group Metal Chalcogenides. Platinum Metals Review 2004, 48, 16-28.

(41) Vorokhta, M.; Khalakhan, I.; Vondráček, M.; Tomeček, D.; Vorokhta, M.; Marešová, E.; Nováková, J.; Vlček, J.; Fitl, P.; Novotný, M.; Hozák, P.; Lančok, J.; Vrňata, M.; Matolínová, I.; Matolín, V. Investigation of Gas Sensing Mechanism of $\mathrm{SnO}_{2}$ Based Chemiresistor Using near Ambient Pressure XPS. Surf. Sci. 2018, 677, 284290.

(42) Giannozzi, P.; Baroni, S.; Bonini, N.; Calandra, M.; Car, R.; Cavazzoni, C.; Ceresoli, D.; Chiarotti, G. L.; Cococcioni, M.; Dabo, I.; Dal Corso, A.; de Gironcoli, S.; Fabris, S.; Fratesi, G.; Gebauer, R.;
Gerstmann, U.; Gougoussis, C.; Kokalj, A.; Lazzeri, M.; MartinSamos, L.; Marzari, N.; Mauri, F.; Mazzarello, R.; Paolini, S.; Pasquarello, A.; Paulatto, L.; Sbraccia, C.; Scandolo, S.; Sclauzero, G.; Seitsonen, A. P.; Smogunov, A.; Umari, P.; Wentzcovitch, R. M. Quantum Espresso: A Modular and Open-Source Software Project for Quantum Simulations of Materials. J. Phys.: Condens. Matter 2009, 21, 395502.

(43) Perdew, J. P.; Burke, K.; Ernzerhof, M. Generalized Gradient Approximation Made Simple. Phys. Rev. Lett. 1996, 77, 3865-3868.

(44) Barone, V.; Casarin, M.; Forrer, D.; Pavone, M.; Sambi, M.; Vittadini, A. Role and Effective Treatment of Dispersive Forces in Materials: Polyethylene and Graphite Crystals as Test Cases. J. Comput. Chem. 2009, 30, 934-939.

(45) Monkhorst, H. J.; Pack, J. D. Special Points for Brillouin-Zone Integrations. Phys. Rev. B 1976, 13, 5188-5192. 